motions. Nonetheless, there remains a small possibility that the result is simply a statistical fluke.

In situations like this, there is no substitute for more data. And more data will certainly come, although they will take several years to gather. In the meantime, cosmologists will scramble to find ways to accommodate this new result, like picnickers sent scurrying by a sudden squall. Most would hope that, as in a thunder- storm, the "hard wind" will eventually die away, and the Universe on large scales will be restored to the tranquil state it seemed to possess just a few short months ago.

August E. Evrard is in the Department of Physics, University of Michigan, Ann Arbor, Michigan 48109, USA. Nick Kaiser is in the Canadian Institute for Theoretical Astrophysics, University of Toronto, $60 \mathrm{St}$ George Street, Ontario, Canada M5S 1A1.

\title{
Whales leave the beach
}

\section{MichaelJ. Novacek}

THE mammalian clade, to which we belong, primarily represents the baroque extravagance of terrestrial adaptations burrowing, galloping, hopping, bipedal walking and tree climbing, not to mention gliding and powered flight, the probable extensions of a lifestyle in the trees. But a few mammals returned to the aquatic milieu of their vertebrate ancestors. In the case of the Order Cetacea, the whales and dolphins, this return to the sea was so decisive that adaptations to swimming, diving and feeding match or surpass those in fishes and sharks. It was a big evolutionary plunge, one that has eluded documentation for many decades.

Things, though, are changing. New discoveries of early fossil whales, such as those of Thewissen et al. (published in Science ) and Gingerich et al. (page 844 of this issue ${ }^{2}$ ), provide striking evidence for both the phylogenetic connections of cetaceans as well as the fascinating mosaic of early adaptive experiments in the transition from land to water. This expanding fossil casebook on the origins of whales is one of the triumphs of modern vertebrate palaeontology.

Intuition may weigh against the notion that something so 'fishy' as a whale may have closest kinship with land mammals. Aristotle, however, was not fooled by intuition; he pointed out that whales and dolphins, unlike bony fish, are livebearing (viviparous). John Ray, in his classic treatise ${ }^{3}$ of 1693 , was more emphatic: "For as except as to the place in which they live, the external form of the body, the hairless skin [sic], and the progressive or swimming motion, they [cetaceans] have almost nothing in common with fishes, but in remaining [characters] agree with viviparous quadrupeds".

Modern systematists have gone some way in refining this concept. The Order Cetacea seems to be related to the great radiation of herbivorous ungulate mammals, and specifically the cloven-hoofed (even-toed) artiodactyls, an order whose modern members include deer, antelope, camels, pigs, giraffes and hippos. The whale-artiodactyl link is supported by anatomical and molecular evidence ${ }^{4-6}$. On the morphological side, further refinement comes from the study of a group of lumbering four-legged mammals, mesonychids, that thrived in the Early Cenozoic and were especially diverse in central Asia ${ }^{4,7}$. There is a general view that mesonychids represent the intermediate lineage between whales and other ungulates ${ }^{7}$ (although this allocation could stand some re-examination). At any rate, mesonychids have served as a bauplan for the evolutionary modifications leading to cetaceans.

Until recent years, the nature of this transition was a matter of inference based on comparison of whales with their putative terrestrial relatives. The gap was filled by a series of discoveries of fossil archaeocete whales ${ }^{8}$. These forms show small pelvic girdles and hindlimbs, whereas modern adult whales retain only vestiges of pelvic and hindlimb elements embedded in the flank musculature. Unfortunately, the adaptive role of these archaeocete hind appendages was uncertain. They seemed of doubtful use in locomotion, but might have functioned as copulatory guides ${ }^{8}$.

A leap in insight comes, however, with Thewissen and colleagues' discovery ${ }^{1}$ of Ambulocetus, a truly remarkable fossil from 52-million-year-old sequences in Pakistan. Ambulocetus can be clearly allied with archaeocetes and other cetaceans, based on features of the middle ear, muzzle, skull roof and teeth ${ }^{1,4}$. Behind the skull, however, the specimen shows an extraordinary combination of features that anticipate, but do not fully embody, the aquatic adaptations of cetaceans. Both front and hindlimbs are well developed, with flexible elbows, wrists, knee joints and digits. The hand is large and elongate and the hind foot is huge. Toes end in hooves as in mesonychids and other ungulates, and the tail is notably long.

Thewissen et al. propose that Ambulocetus was amphibious; that it was possibly awkward but mobile on land, and adept at swimming. The long tail suggests that this creature lacked a fluke, and from the shape of the lumbar vertebrae it seems that the creature swam by undulations of its vertebral column. The large paddle-like hind feet were thrust through the water when the back was flexed and extended. Unlike seals, however, the plane of undulation was not mediolateral but dorsoventral, as in living cetaceans. The forelimbs were probably involved in steering but not propulsion. It seems logical that whales may have gone through a seal-like amphibious stage early in their evolution, but the direct evidence for such a phase, as represented by Ambulocetus, is extraordinary.

A seaward shift beyond Ambulocetus is dramatically exemplified by the Eocene whale, Rodhocetus, now described by Gingerich et al. ${ }^{2}$. Rodhocetus is geologically younger than Ambulocetus and also shows a more specialized apparatus for swimming. Its short cervical vertebrae, large unfused sacral vertebrae and reduced femur are derived features associated with adeptly swimming archaeocetes and modern whales. At the same time, Rodhocetus retains features of the vertebral column and pelvic girdle that hark back to terrestrial relatives ${ }^{2}$. So it was not amphibious like Ambulocetus, but did show a mosaic of aquatic and terrestrial traits. The new specimen also casts light on early whale habitats, in that the animal was found in rocks that indicate deepwater (neritic) environments. To date, early archaeocetes have been limited to near-shore deposits, and so Rodhocetus demonstrates early variations in both locomotion and distribution. Indeed, the diversified lifestyles revealed by these early fossils suggest that whale evolution got off to a very quick start.

Ambulocetus, Rodhocetus and other more aquatically specialized archaeocetes cannot be strung in procession from ancestor to descendant in a scala naturae. Nonetheless, these fossils are real data on the early evolutionary experiments of whales. They powerfully demonstrate transitions beyond the reach of data, whether molecular or morphological, derived from living organisms alone.

Michael J. Novacek is at the American Museum of Natural History, Central Park West at 79th Street, New York. New York 10024, USA.

1. Thewissen, J. G. M., Hussain, S. T. \& Arif, M. Science 263 210-212 (1994)

2. Gingerich. P. D. Raza, S. M., Arif, M. . Anwar, M. \& Zhou, X Nature 368, 844-847 (1994).

3. Ray, J. Synopsis Methodica Animalium Quadrupedum et Serpentini Generis, 8 (London, 1693).

4. Berta. A. Science 263, 180-181 (1994).

5. Milinkovitch. M. C., Orti, G. \& Meyer. A. Nature 361. 346-348 (1993)

6. Novacek. M. J. Nature 356, 121-125 (1992)

7. Van Valen, L. Bull. Am. Mus, nat. Hist. 132, 1 (1966)

8. Gingerich, P. D., Smith, B. H. \& Simons, E. L. Science 249. $154-157(1990)$ 